\title{
Proposal for describing procedures to correct varicocele. A new terminology
}

\author{
Ricardo González ${ }^{1,2}$ * \\ 1 Pediatric Surgery and Urology, Auf der Bult Kinder und Jugendkrankenhaus, Hannover, Germany \\ 2 Urology and Pediatric Surgery, Universitätsmedizin Berlin - Charité Virchow Klinikum, Berlin, Germany \\ ${ }^{*}$ Correspondence: ricardo_gonzalez33154@yahoo.com \\ Edited by: \\ Alexander Springer, Medical University Vienna, Austria \\ Reviewed by: \\ Marcos Raymond Perez-Brayfield, University of Puerto Rico, USA \\ Imran Mushtaq, Great Ormond Street Hospital for Children, UK
}

Keywords: varicocele, varicocele operations, Ivanissevich procedure, Palomo procedure, eponyms

Although the use of eponyms to describe specific surgical operations is often discouraged (1), the custom is so deeply ingrained in medical writing that readers inevitably encounter them. Therefore, for the sake of clarity in communications, one should strive to be correct in their use.

A classic case of perpetuation of misinformation is the use of eponyms to describe the operations performed to correct varicocele.

Most seemingly authoritative reviews repeatedly state that the eponym "Ivanissevich procedure" refers to the transinguinal ligation of the spermatic vein. This is a mistake and is repeated through the published literature since access to the original papers may require an additional effort rarely made in this era of computerized searches (2-5).

\section{HISTORICAL REVIEW}

In 1918, Dr. Oscar Ivanissevich working in Buenos Aires described the anatomy of the spermatic vein and proposed a suprainguinal approach to spermatic vein ligation (6). The rationale for this approach was to ligate the vein where it was most likely to have a single trunk. In 1960, he reported his experience with more than 4000 cases using the suprainguinal approach in an English language journal and provided detailed illustration of his technique (7) (Figure 1).

It was actually Bernardi, a disciple of Ivanissevich who advocated a transinguinal approach to spermatic vein ligation (8). In his 1960 article, Ivanissevich is critical of Bernardi's transinguinal approach but admits that for inexperienced surgeons it might be easier than the retroperitoneal. He further stated that one should still strive to ligate the vein above the internal inguinal ring.

In 1949, Palomo described the ligation of the spermatic vein and artery through a retroperitoneal approach. He reported preliminary results but a more definitive article never followed. Although he gives no credit to Ivanissevich for the approach, being Spanish-speaking, it is unlikely that he was not aware of Ivanissevich's work. Some authors have mistakenly applied the term "modified Palomo" procedure for the retroperitoneal approach preserving the artery (9) when in reality this is no other than the procedure described by Ivanissevich.

A possible reason for these errors is that the original articles are no easy to locate and there are no abstracts attached to the titles in PubMed and authors quote others who also have not personally read the references.

In summary, the correct terminology, based on a review of the full-text original articles is:

Suprainguinal approach ligation of only the vein: Ivanissevich.

Suprainguinal approach ligation of artery, vein, and lymphatics: Palomo.

Inguinal approach with ligature of the vein or veins: Bernardi.

However, considering that there are approaches other than open operations that are gaining popularity such as the transvascular venous occlusion (10) and laparoscopic vein ligation (11), and for the sake of clarity, I propose the following terminology to describe varicocele operations which includes the description of the approach, what is done, and the use of optical aids.

\section{Approach:}

Subinguinal

Inguinal

Suprainguinal (retroperitoneal)

Laparoscopic

Transvenous

\section{What is occluded:}

Vein

Artery and vein

Artery, vein, and lymphatics

\section{Optical magnification:}
None
Loupes
Microscope
Laparoscopy

If this terminology is accepted and widely adopted, publications addressing this still controversial topic would be easier to interpret.

\section{ACKNOWLEDGMENTS}

Presented at the 24th Annual Congress of the European Society for Paediatric Urology, Genoa, Italy. 


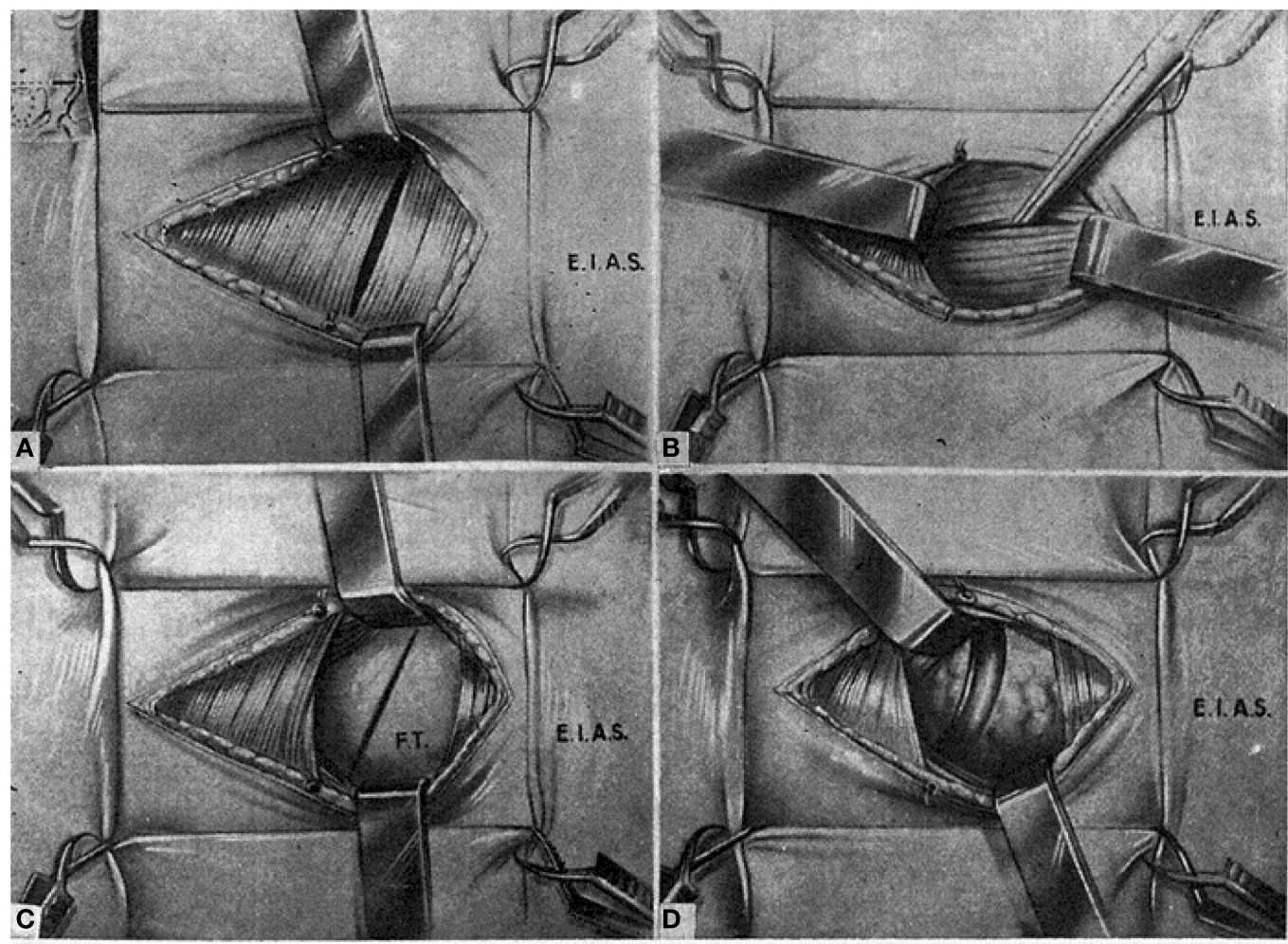

Fig. 4.- $A$, horizontal incision to locate spermatic vein, immediately above internal or external inguinal orifice (second technic published by author and his collaborators); separation of fibers of greater oblique muscle. $B$, separation of fibers of lesser oblique and transversus muscles at level of internal orifice of inguinal canal. $C$, section of transversalis fascia. $D$, fixation of vessel trunks and single trunk of spermatic vein to peritoneum by cellular tissue.

FIGURE 1 |The figure from Ivanissevich's 1960 paper (7) clearly shows that the incision (first described in the 1918 paper) is medial to the anterior superior iliac spine, thus a suprainguinal or retroperitoneal approach (presented at the 24th Annual Congress of the European Society for Paediatric Urology, Genoa, Italy). With permission from International College of Surgeons.

\section{REFERENCES}

1. Taylor R. Medical Writing: A Guide for Clinicians, Educators, and Researchers. 2nd ed. New York: Springer (2011).

2. Glassberg KI, Korets R. Update on the management of adolescent varicocele. F1000 Med Rep (2010) 12(2):25. doi:10.3410/M2-25

3. Diamond D, Xuewu J, Cilento B, Bauer S, Peters C, Borer J, et al. Varicocele surgery: a decade's experience at a children's hospital. BJU Int (2009) 104(2):246-9. doi:10.1111/j.1464-410X. 2008.08288.x

4. Fayez A, El Shantaly K, Abbas M, Hauser S, Müller S, Fathy A. Comparison of inguinal approach, scrotal sclerotherapy and subinguinal antegrade sclerotherapy in varicocele treatment: a randomized prospective study. Urol Int (2010) 85(2):200-3. doi:10.1159/000316338

5. Raheem O. Surgical management of adolescent varicocele: systematic review of the world literature. Urol Ann (2013) 5(3):133-9. doi:10.4103/ 0974-7796.115728
6. Ivanissevich O, Gregorini H. A new operation for the cure of varicocele. Semana Medica (1918) 61:17.

7. Ivanissevich O. Left varicocele due to reflux; experience with 4,470 operative cases in forty-two years. I Int Coll Surg (1960) 34:742-55.

8. Bernardi R. Ivanissevich's anatomical concept of the cure of varicocele: some modifications in its technique. Bol Inst Clin Quir (1941) 13:521.

9. Barroso UJ, DM A, Novaes H, Netto J, Andrade J. Surgical treatment of varicocele in children with open and laparoscopic Palomo technique: a systematic review of the literature. J Urol (2009) 181(6):2724-8. doi:10.1016/j.juro.2009.02.041

10. Formanek A, Rusnak B, Zollikofer C, CastanedaZuniga W, Narayan P, Gonzalez R, et al. Embolization of the spermatic vein for treatment of infertility: a new approach. Radiology (1981) 139(2):315-21.

11. Aaberg R, Vancaillie T, Schuessler W. Laparoscopic varicocele ligation: a new technique. Fertil Steril (1991) 56(4):776-7.
Conflict of Interest Statement: The author declares that the research was conducted in the absence of any commercial or financial relationships that could be construed as a potential conflict of interest.

Received: 01 May 2014; accepted: 11 May 2014; published online: 30 May 2014.

Citation: González R (2014) Proposal for describing procedures to correct varicocele. A new terminology. Front. Pediatr. 2:47. doi: 10.3389/fped.2014.00047

This article was submitted to Pediatric Urology, a section of the journal Frontiers in Pediatrics.

Copyright () 2014 González. This is an open-access article distributed under the terms of the Creative Commons Attribution License (CC BY). The use, distribution or reproduction in other forums is permitted, provided the original author(s) or licensor are credited and that the original publication in this journal is cited, in accordance with accepted academic practice. No use, distribution or reproduction is permitted which does not comply with these terms. 